\title{
The behaviour of managers in Austria and the Czech Republic: An intercultural comparison based on the Vroom/Yetton Model of leadership and decision making*
}

\author{
Gerhard Reber, Werner Auer-Rizzi, Milan Maly ${ }^{* *}$
}

In this paper we compare the leadership behaviour of managers in Austria and the Czech Republic, employing the Vroom/Yetton situational leadership model. The model applies a methodology that is close-to-action in contrast to the collection of empirical data based on questionnaires, which target the revelation of basic values as determinants of intercultural differences (farfrom-action), such as the studies of Hofstede and the GLOBE-Project. The results show that leadership behaviour in the Czech Republic remains autocratic despite dramatic changes in the societal and political environment of the two countries.

In diesem Aufsatz vergleichen wir das Führungsverhalten von Managern in Österreich und der Tschechischen Republik anhand des Vroom/Yetton situationsbezogenen Führungsmodells. Das Modell nutzt eine Methodik, die praktisch ist im Vergleich zur Sammlung von empirischen Daten, die auf Fragebögen basieren und welche die Enthüllung von Grundwerten als Determinanten von interkulturellen Unterschieden (theoretisch) wie die Studien von Hofstede und das GLOBE-Projekt zum Ziel hat. Die Ergebnisse zeigen, dass dass Führungsverhalten in der Tschechischen Republik immer noch autokratisch ist, trotz dramatischer Veränderungen sowohl im sozialen als auch im politschen Umfeld in beiden Ländern.

Key words: Leadership behaviour, participation, Czech Republic, Austria, cross cultural studies

* Manuscript received: 17.09.03, accepted: 16.06.04 (1 revision)

** Gerhard Reber, born 1937, Professor, University of Linz. Main research interests: Organizational behaviour, leadership.

Werner Auer-Rizzi, born 1960, Professor, University of Linz. Main research interests: Organizational behaviour, decision-making, trust.

Milan Maly, born 1936, Professor, University of Economics Prague. Main research interests: Organizational architecture, management in transition, corporate governance. Corresponding address: Maly@vse.cz 


\section{Introduction ${ }^{1}$}

The extension of the European Union began on May $1^{\text {st }} 2004$. This event will bring about not only new problems but also new opportunities for the existing and new members of the EU. The new opportunities can be realised after the different nations find a way to cooperate. For this cooperation, it is very important that cultural differences be mastered. This is a challenge in all areas of management including marketing, accounting, finance, production and so forth. A key factor among these topics is leadership behaviour. The successful cooperation between companies in the new environment must be implemented by business leaders. Our study will focus on this area.

In addition to practical implications, the study will address methodological problems. Obviously, there is much anecdotal knowledge about cultural differences between neighbouring states and shared within the different countries. However, they contain many prejudices and errors, and systematic empirical studies are seldom conducted. Among the small selection of studies, different approaches were also used. The first part of this paper will provide a brief overview on the characteristics of these studies. We will argue in favour of a model, which takes a 'close-to-action' methodology into consideration. In line with that methodology we will apply the Vroom/Yetton model of leadership decision-making and this model will be explained in detail. An empirical application of the model will be used to answer our research question which seeks to explain the cultural differences in leadership behaviour of managers from the Czech Republic and Austria.

\section{Cross-Cultural Studies: Value Concept Versus Action Orientation}

Empirical studies of cross-cultural differences in leadership behaviour are rare (House et al. 1997). The most classical studies were done by Geert Hofstede (1980; 2001; Hofstede/Bond 1988) and are still quoted today in many relevant textbooks. Hofstede's analyzed data were collected between 1967 and 1973 by IBM subsidiaries in sixty-four countries. Subsequently he added ten country regions to his data pool, which correspond to twenty-three today. Hofstede's theoretical concept is oriented on 'basic values', which he views as the deepest level of a culture. According to Hofstede, these values are embedded in the individual by the country in which he/she is born and socialized. In comparison to cross-national differences, the cultural dimensions of a profession or an organisation are seen as superficial on the level of symbols, heroes and rituals.

1 This article presents one of the outcomes of the research activities of the authors sponsored by AKTION program Czech Republic - Austria, cooperation in science and education 
Initially Hofstede differentiated four, later the following five, dimensions of national cultures: 1. Power Distance, 2. Individualism versus Collectivism, 3. Masculinity versus Femininity, 4. Uncertainty Avoidance and 5. Short-term versus Long-term Orientation. In addition to anchoring the configuration of leadership behaviour in the attributes of the culture of the relevant nation, Hofstede is convinced that this behaviour exhibits strong inertia and thus high resistance to change. As far as the methodology is concerned, Hofstede employed traditional quantitative empirical research to select five dimensions using factor analysis.

Hofstede's work was not challenged for a long period. However, in 1994 Robert House initiated the GLOBE ('Leadership and Organizational Behaviour Effectiveness Research Program') project. The GLOBE Project was conducted by 150 researchers from 60 countries (House et al. 1997; House et al. 1999). In terms of its broad conception, this project directly followed in Hofstede's footsteps. The basic value orientation as well as the main methodology remained unchallenged. During the research efforts, the quality of Hofstede's dimensions and their quantitative operationalisation were criticised and improved. The core results of this attempt led to the identification of nine culture dimensions: 1. Uncertainty Avoidance, 2. Power Distance, 3. Collectivism I, 4. Collectivism II, 5. Gender Egalitarianism, 6. Assertiveness, 7. Future Orientation, 8. Performance Orientation, 9. Humane Orientation. The latter is defined as the degree to which a group encourages and rewards individuals for being fair, altruistic, generous, caring and kind to each other. The initiators of the GLOBE-Project did not draft a complete theory of the culture; they accepted the eclectic and not very systematic theoretical limits of Hofstede's work. As far as leadership theories are concerned, the concept of charismatic leadership and the attribution theory of leadership are the theoretical models that come closest to the GLOBE-Project, in which 'implicit leadership theory' is one of the targets of research. 'Leadership is defined [...] as the ability of an individual to influence, motivate and enable others to contribute toward the effectiveness and success of the organization of which they are members' (House et al. 1997: 220).

Parallel to the start of the GLOBE-Project, Trompenaars (1993) surveyed more than 10,000 managers in nearly fifty nations, with particular emphasis upon Europe and eight ex-communist nations, among others former Czechoslovakia. Trompenaars' (1993) questionnaire includes items addressing seven hypothesised dimensions of cultural valuing. Thus he shares the value orientation; but in contrast to the GLOBE project he intentionally avoided conceptually replicating Hofstede's dimensions. This was done to challenge the quality of the dominating classification and to check the replicability of the results of these older dimensions (Smith et al. 1996). 
The original seven dimensions which Trompenaars derived from earlier theorizing by sociologists and anthropologists were reduced to two in subsequent studies, since it appeared that some of the dimensions were strongly correlated with one another (Smith et al. 1996).

"The first of the two dimensions can be thought of as representing "hierarchy" versus "equality". Nations whose managers score high on hierarchy are those in which power differences are accepted, paternalism is expected, job appointments are likely to be on the basis of ascribed qualities, and preferential treatment is given to one's immediate associates. Nations whose managers score high on equality are those in which work is evaluated and appointments are made on the basis of objective criteria which are applied equally to all persons. The second dimension distinguishes "involvement" from "autonomy". Nations whose managers score high on involvement are those in which one's identity is defined in terms of one's long-term commitment to the organization. Nations whose managers score high on autonomy are those where job involvement is seen as dependent upon a calculus of one's current rewards, career prospects and alternative opportunities' (Smith 1997: 377).

Comparing their results with Hofstede's earlier study, Smith et al. (1996) found that scores on both of their dimensions were to some extent associated with Hofstede's scores for 'Power Distance' and 'Individualism-Collectivism'. As far as country differences are concerned, they found a striking feature: the former communist nations of the Central Europe cluster are all characterized by combinations of 'hierarchy' and 'autonomy' in contrast to the West European nations which are characterized by the combination of 'equality' and 'involvement' (Smith et al. 1996: 247).

Two conclusions emerge from this first comparison on Hofstede's and Trompenaars' data bases. First, the links found between both Hofstede's dimensions and the two dimensions extracted by Smith et al. (1996) provide some evidence of continuity in different approaches to management in the different nations of the world. The two studies used very different samples of respondents, different instruments, and were completed at different times. The fact that their results nonetheless showed some convergence is a persuasive indication that the global variations found by Hofstede are still there, even if they may have decreased in magnitude. The second conclusion comes directly from the inclusion of former communist nations within Trompenaar's samples. The data from these countries were collected in the late 1980s. The scores obtained confirm what many would have expected, namely that the major variability in approaches to management within Europe lies between East and West. 'The footprint of history which appears to leave the sharpest imprint at present is not that of the Roman Empire, but that of the Soviet Empire. These data do not of course establish that conclusion unequivocally. There may have been major divergences in approaches to management between Eastern and 
Western Europe long before the end of the Second World War' (Smith 1997: 377-78).

Thus, the road through major value-oriented studies, despite some missing data and a detour around the neglect of Central European countries, seems to lead to some coherent results. Their relevance can be limited by the common reliance on the 'value' concept. This orientation can be challenged by doubts that values may be illusions but not predictors of overt behaviour. 'Values' can be seen as a 'far-from-action' concept with a 'relative distance' from 'close-to-action' concepts such as intended behaviour, commitment or volition (Szabo et al. 2001). A 'close-to-action' approach involves the investigation of actual leadership behaviour across cultures and includes basic values as well as situational factors. Value-oriented and action oriented research can come to matching outcomes, as for example, Jago et al. (1995) demonstrated for their high Power-Distance prediction in the case of Czechoslovakia and Poland, using the action-oriented Vroom/Yetton model. However, value-oriented and action-oriented research methods can also result in divergent results. For example, the findings of diversity within the countries of the former communist countries in Smith and Peterson's (1995) action-oriented 'event-management' study contradict the value-oriented results of the Trompenaars (1993) data, which led Smith (1997) to his statement of the overpowering 'inprint' of the as he calls it - 'Soviet Empire'.

Another example of a 'close-to-action' approach is the 'cultural standards' method, developed by Thomas (1996), which describes the frame of orientation guiding perception, thinking, and action in a specific culture (society, group). The key approach of this method pertains to its data gathering and interpretation. The emphasis is not on interviewing people from the specific culture under study but on obtaining from foreigners reports of critical incidents that deviate from their expectation of that culture on a day-by-day basis. The interdisciplinary analyses of these incidents then lead to the formulation of the perceived standards. They are not a general description of the foreign culture, but point to norms, which are relevant for action in that culture and are perceived as different to one's own culture. Thus they can only be seen as a contrast between two cultures and are domain-specific. For example, Novy and Schroll-Machl (2003) describe the Czech cultural standards (in contrast to Germany): downplaying of formal structures (flexibility, improvisation), simultaneousness, person centred control (in contrast to rule centred control), diffusion of spheres, high context communication, conflict avoidance, and unsteady self-confidence.

The cultural standards method has not focused on the contingencies of leadership situations. Such a focus seems to be very promising for future research. 


\section{The Vroom/Yetton Model}

The Vroom/Yetton (1973) model comprises three elements which are interconnected in the logic of the contingency theory: There is (1) no leadership strategy (style) which is successful in all situations, (2) therefore the situations have to be diagnosed and (3) rules have to be found that explain which strategy best matches which situation. The Vroom/Yetton model has been tested in a number of studies and is perhaps the best supported of the situational leadership theories. In this section we give a brief introduction for better understanding the results of this study.

(1) Leadership strategies: According to the model, a leader can choose from five levels of participation when making a decision (AI, AII, CI, CII, GII). These strategies range from a autocratic decision (AI) to a total group decision (GII). AI represents $0 \%$ and GII $100 \%$ participation. The assignment of different participation scores for the strategies between the extremes of the scale is based on empirical studies in which managers rate the distances on a 1 to 10 scale. As a result, AII represents $10 \%$, CI $50 \%$ and CII $80 \%$ participation. 'A' stands for autocratic, ' $\mathrm{C}$ ' for consultative and ' $\mathrm{G}$ ' for group decision. ' $\mathrm{I}$ ' stands for the concentration on one person ( $\mathrm{AI}=$ leader alone, $\mathrm{CI}=$ one-on-one consultation with all subordinates who could be affected by the decision), and 'II' stands for the inclusion of two or more persons at the same time.

\section{Table 1. Decision Strategies}

AI You solve the problem or make the decision yourself using the information available to you at the present time

AII You obtain any necessary information from subordinates, then decide on a solution to the problem yourself. You may or may not tell subordinates the purpose of your questions or give information about the problem or decision you are working on. The input provided by them is clearly in response to your request for specific information. They do not play a role in the definition of the problem or in generating or evaluating alternative solutions.

CI You share the problem with the relevant subordinates individually, getting their ideas and suggestions without bringing them together as a group. Then you make the decision. This decision may or may not reflect your subordinates` influence.

CII You share the problem with your subordinates in a group meeting. In this meeting you obtain their ideas and suggestions. Then you make the decision, which may or may not reflect your subordinates' influence.

GII You share the problem with your subordinates as a group. Together you generate and evaluate alternatives and attempt to reach agreement (consensus) on a solution. Your role is much like that of a chairperson, coordinating the discussion, keeping it focused on the problem and making sure that the critical issues are discussed. You can provide the group with information or ideas that you have, but you do not try to 'press' them to adopt 'your' solution and you are willing to accept and implement any solution, which has the support of the entire group.

Source: Vroom / Yetton (1973) 
(2) Situational Attributes: The leadership decision situation is characterised by seven attributes, which correspond to seven diagnostic questions: (A) Does the problem possess a quality requirement? (B) Does the leader have sufficient information to make a high quality decision? (C) Is the problem structured? (D) Is acceptance of decision by subordinates important for effective implementation? (E) Will an autocratic decision made by the leader be accepted by subordinates? (F) Do subordinates share the organizational goals to be attained in solving this problem? (G) Is conflict among subordinates over preferred solutions likely? The seven questions rely on the assumption that leadership effectiveness is based on mastering two main variables: $L E=f(Q x$ A) where Q stands for 'quality' and A for 'Acceptance'. Quality refers to a leader's professional competence, with emphasis on knowledge, to meet the 'technical' and task-oriented requirements of an organisational goal. Acceptance refers to the subordinate's commitment to execute the organisational goals. A commitment of this kind is endangered when subordinates are in conflict with the leader's aspirations, the company's goals, or when they do not find adequate consensus among themselves on how to tackle the task at hand. The leader needs 'social competence' to diagnose these commitment problems.

(3) Decision Rules: The model provides seven decision rules (Leader Information Rule, Goal Congruence Rule, Unstructured Problem Rule, Acceptance Rule, Conflict Rule, Fairness Rule, Acceptance Priority Rule), each one of them excluding certain decision strategies in specific situations. The Leader Information Rule, for example, eliminates strategy AI (autocratic decision making) from being feasible in a situation, where the quality of the decision is important (diagnostic question $\mathrm{A}=$ 'yes') and the leader does not have enough information or expertise to solve the problem alone (diagnostic question $\mathrm{B}=$ 'no'). The result of applying all the seven rules to a decision situation is a set of strategies (feasible set) for that situation. When the feasible set contains more than one strategy, there are two additional criteria to focus on just one strategy - time and subordinate development. According to 'Model A' the most time saving (least participative) feasible strategy is always selected from the feasible set. 'Model B' replaces the goal of time efficiency with a goal of subordinate development and selects the most participative feasible strategy which provides greater involvement of subordinates in decision making and more opportunities to develop their own managerial, technical and team skills. 


\section{Table 2. Decision Rules}

\section{Leader Information Rule $\mathrm{A}+\not \mathbf{D}$}

If the quality of the decision is important and the leader does not possess enough information or expertise to solve the problem alone, then $\mathrm{AI}$ is eliminated from the feasible set.

\section{Goal Congruence Rule A $+\not$}

If the quality of the decision is important and subordinates are not likely to pursue the organization goals in their efforts to solve this problem, then GII is eliminated from the feasible set.

\section{Unstructured Problem Rule $\mathrm{A}+\not \mathbf{B}+\not \subset$}

In situations in which the quality of the decision is important, if the leader lacks the necessary information or expertise to solve the problem alone, and if the problem is unstructured, the method of solving the problem should provide for information among subordinates likely to possess relevant information. Accordingly, AI, AII and CI, which provide no interaction among subordinates, are eliminated from the feasible set.

\section{Acceptance Rule $\mathrm{D}+\not 2$}

If the acceptance of the decision by subordinates is important for effective implementation and if it is not reasonably certain that an autocratic decision will be accepted, AI and AII are eliminated from the feasible set.
5. Conflict Rule
$\mathrm{D}+\not \mathscr{E}+\mathrm{G}$

If the acceptance of the decision is important, an autocratic decision is not reasonably certain to be accepted and disagreement among subordinates over possible solutions is likely, the methods used in solving the problem should enable those in disagreement to resolve their differences with full knowledge of the problem. Accordingly, under these conditions, AI, AII and CI, which permit no interaction among subordinates and therefore provide no opportunity for those in conflict to resolve their differences, are eliminated from the feasible set. Their use runs the risk of leaving some of the subordinates with less than the needed commitment to the final decision.

\section{Fairness-Rule $\not \not X+D+\not \subset$}

If the quality of the decision is unimportant, but acceptance of the decision is important, and not reasonably certain to result from an autocratic decision, the decision process used must generate the needed acceptance. The decision process should permit the subordinates to interact with one another and negotiate among themselves over the method of resolving any differences with full responsibility on them for determining what is fair and equitable. Accordingly, under these circumstances, AI, AII, CI and CII are eliminated from the feasible set.

\section{Acceptance Priority Rule $\mathrm{D}+\not z+\mathrm{F}$}

If acceptance is important, not reasonably certain to result from an autocratic decision and if subordinates are motivated to pursue the organizational goals represented in the problem, then methods which provide equal partnership in the decision making process can generate far greater acceptance without risking decision quality. Accordingly, AI, AII, CI and CII are eliminated from the feasible set.

Source: Vroom / Yetton (1973) 


\section{Cross-Cultural Comparison of Austrian and Czech Managers}

\subsection{Method and Data Collection}

The applied method and data collection were dominated by a clear action orientation. No questionnaire was used and all data were collected by administering a 'problem set' in the form of thirty decision-making situations. The thirty cases were selected and rewritten from actual descriptions of real decisions provided to the authors (Vroom/Yetton/Jago 1976) by hundreds of real managers and were validated with the assistance of trained managers. If eight out of ten of those trained managers detected the same problem attributes within the same case, a sufficient validation was assumed. This test, applied for the English problem set (Jago/Vroom 1978) was repeated in a German version (Böhnisch 1991). For the Czech studies, a translation of the thirty cases by native speakers was used; the semantic 'corrections' were not tested systematically. However, in discussions with the Czech managers during their training program, one of the authors in charge of the feedback session got the impression of a 'face validity' of the translations as the author found that the same problem attributes were mentioned.

The problem set was administered to managers who, at the time of data collection, were unfamiliar with the Vroom/Yetton model. In addition to the cases, they only received the definition of the five strategies and were asked to select one for each case. An average time of two hours was needed to read the cases and to make the thirty decisions.

The results of the decision process mirror intended behaviour. Validation studies conducted by Jago and Vroom (1978) for the US and replicated by Böhnisch et al. (1988) for Austria came to the conclusion that the intended behaviour as a reaction to the problem set iss equivalent to the real behaviour of the involved managers.

The Czech and Austrian data were collected prior to leadership training programs. In such a training program, the respondents were not providing a 'favour' for the researchers since their main concern was the improvement of their own leadership behaviour. All of the participants received feedback, in which their first reactions to the problem set were compared to a description of the model. Training was provided to assist the participants in using the diagnostic questions and the decision rules for upcoming leadership decisions in their home organisational environment.

The data collection in Austria began in 1984 and in the Czech Republic in 1991 with the most recent data collected in Prague in Summer of 2003. The total numbers (2863 managers in Austria and 710 in the Czech Republic) were standardised based on a matching process. Matching was performed on organisational and demographic variables - provided by the respondents known to affect leadership style: gender, hierarchical level, managerial 
function, age, as well as organisation type, number of subordinates, and tenure with the company.

\subsection{Results}

Participativeness: The most straightforward of problem set statistics are the simple "frequencies with which managers choose each of the five strategies". The top part of Table 3 contains the means from the two cultures. The comparison confirms the finding that Austrian managers are less inclined to employ autocratic strategies (AI and AII) while they most frequently use group processes (CII and GII) for decision-making. Czech managers differ significantly from the Austrians in the use of consultative group processes (CII) and the consensus seeking strategy (GII). As far as the CI strategy is concerned no differences were found; both countries show this strategy with the second lowest frequency. The CI-Strategy is the only strategy in which managers in both countries showed no significant difference. While there seems to be a common 'need' for this strategy, this does not reveal for what purpose a consultative private conversation between the manager and subordinate might take place in the two countries.

Based on the participation score of the chosen strategies, a 'mean level of participation (MLP)' can be computed. In our study it is not computed on the individual level (which reveals a personality factor), but rather as an average on the national level. In addition, the standard deviation (SD) around the average is computed again on the national level. The SD demonstrates flexibility: the higher the score - the maximum on the participation scale being between AI (0) and GII (10) is 5.0 - the higher the variance of strategies.

The value of the MLP score and the standard deviation are found at the bottom of Table 3. The table indicates that the Czech show a significantly lower MLP in comparison with Austrians. It is interesting to note that the Czech possess a slightly higher SD than the Austrians. This confirms the assumption (based on the GLOBE data) that Czech managers possess a high degree of flexibility as a whole, which can be interpreted - as already mentioned - as a sign of readiness for change processes. 
Table 3. Participativeness

\begin{tabular}{|c|c|c|c|c|}
\hline \multirow[t]{2}{*}{ Variable } & A & $\mathrm{CZ}$ & \multirow[t]{2}{*}{ F-Value } & \\
\hline & (158) & $(158)$ & & \\
\hline \multicolumn{5}{|l|}{ Percent Use of Strategies: } \\
\hline Al - Autocratic & 19,6 & 25,5 & 20,42 & ** \\
\hline All - Autocratic & 14,9 & 20,9 & 41,58 & ** \\
\hline $\mathrm{Cl}$ - Consultative & 16,0 & 15,8 & 0,09 & \\
\hline CII - Consultative & 29,6 & 24,3 & 24,22 & ** \\
\hline GII - Group Decision & 19,9 & 13,6 & 39,84 & ** \\
\hline Mean Level of Participation & 5,31 & 4,30 & 65,06 & ** \\
\hline Standard Deviation & 3,64 & 3,69 & 1,39 & \\
\hline${ }^{*} p<0,05 \quad * *=p<0,01$ & & & & \\
\hline
\end{tabular}

Agreement with Normative Model: Table 4 reports the mean frequencies with which Austrian and Czech responses fell within the feasible set across the thirty cases. Austrian managers outperform their colleagues in the Czech Republic with a very high F-Value; Austrian and Czech managers show the same degree of agreement with Model A (time efficiency) but a big difference with the use of Model B (subordinate development).

Each time a respondent's choice is outside the 'feasible set', that choice has violated one or more of the seven decision rules underlying the normative model. Rates of rule violations are also reported in Table 4 . These data isolate the sources of disagreement between managers and model behaviour. For six of the seven rules, Austrian respondents display a lower rate of violation than Czech respondents; the Czech and Austrian managers are congruent in Rule 2. This rule excludes the GII strategy in a situation in which quality is at stake and the subordinates do not share the organizational goals. The violation of Rule 2 has the lowest frequency and is the only one to show no significant differences between the two countries.

As previously stated, rules $1-3$ are designed to protect decision quality whereas rules 4 - 7 are designed to protect decision acceptance. Rates of quality rule violations (appropriately adjusted for the frequency of rule applicability) and rates of acceptance rule violations are also included in Table 4. 


\section{Table 4. Agreement with the Vroom/Yetton Model}

\begin{tabular}{|c|c|c|c|c|}
\hline \multirow[t]{2}{*}{ Variable } & \multirow{2}{*}{${ }_{(158)}^{A}$} & \multirow{2}{*}{$\begin{array}{c}C Z \\
(158)\end{array}$} & \multirow[t]{2}{*}{ F-Value } & \\
\hline & & & & \\
\hline \multicolumn{5}{|l|}{ Percent Agreement with: } \\
\hline Feasible Set & 72,4 & 66,4 & 42,70 & ** \\
\hline Model A Choice & 37,9 & 36,4 & 1,64 & \\
\hline Model B Choice & 29,6 & 20,4 & 63,64 & ** \\
\hline \multicolumn{5}{|l|}{ Percent Rule Violations: } \\
\hline Rule 1 - Leader Info, & 9,9 & 12,1 & 3,61 & * \\
\hline Rule 2 - Goal Congruence & 11,5 & 7,7 & 10,43 & ** \\
\hline Rule 3 - Unstructured & 36,3 & 48,3 & 25,45 & ** \\
\hline Rule 4 - Acceptance & 16,6 & 30,1 & 69,00 & ** \\
\hline Rule 5 - Conflict & 34,1 & 51,1 & 47,41 & ** \\
\hline Rule 6 - Fairness & 30,4 & 60,4 & 66,05 & ** \\
\hline Rule 7 - Accept, Priority & 62,2 & 70,6 & 8,50 & ** \\
\hline Quality Rules (1-3) & 15,8 & 17,6 & 5,75 & * \\
\hline Acceptance Rules (4-7) & 30,7 & 45,7 & 85,43 & ** \\
\hline${ }^{*} p<0,05 \quad * *=p<0,01$ & & & & \\
\hline
\end{tabular}

The first conclusion to be drawn from aggregating rule violations is that regardless of culture, departures from the model's prescriptions are more likely to be attributed to violations of acceptance rules rather than of the quality rules. This is consistent with the evidence in all studies completed within the framework of the Vroom/Yetton model (Vroom/Yetton 1973; Vroom/Jago 1988; Reber et al. 1993; Maczynski et al. 1994; Reber et al. 2000) and seems to have specific signals for the education process concerning future managers. The deficits are significantly higher in the area of social rather than in the area of 'professional' (in the tradition of a narrow 'task' orientation, respectively technical qualities of decisions).

Nonetheless, significant differences exist between the two countries. Austrian managers display significantly lower rates of acceptance violation in comparison to Czech.

Attribute Main Effects: Based on the diagnostic questions, main effects are reported in Table 5. The main effects show behavioural differences that take place when the attribute is absent versus present. A positive main effect indicates a behavioural tendency to be more participative when the attribute is present (i.e. when the answer to the diagnostic question is 'Yes'), a negative main effect indicates the reverse. The results portray a relatively complicated picture. At a first glance into the dimensions of the quality requirement, Austrian and Czech managers are more participative when the problem at hand 
contains a quality component and is, from the organisation's perspective, nontrivial. On the other hand, they display greater autocracy on the organizationally trivial issues.

In situations in which leaders do not have sufficient (technical, professional) information, an inclination to become less participative is increasingly apparent among Austrian managers $(-0.47)$ in comparison to Czechs $(-0.73)$. If the situation is unstructured, the tendency for autocratic reactions to decrease is stronger in Austria than in the Czech Republic. In situations where acceptance of the subordinates is important, Austrian managers tend to use participative styles to a higher degree than managers in the Czech Republic - although the difference is not significant. In situations where leaders and subordinates are in conflict, Austrian managers become significantly more participative than their colleagues in the Czech Republic. If the conflict is between subordinates, Czech managers consider it appropriate to become more autocratic than the Austrian managers.

\section{Table 5. Attribute Main Effects}

\begin{tabular}{lcccc}
\hline Variable & A & $\begin{array}{c}\text { CZ } \\
(158)\end{array}$ & F-Value & \\
& $(158)$ & & & \\
\hline Situational Main Effects: & & & & \\
$\quad$ Quality Requirement & 0,66 & 0,90 & 1,81 & \\
Leader Information & $-0,47$ & $-0,73$ & 2,87 & \\
Problem Structure & $-1,72$ & $-1,59$ & 0,39 & \\
Acceptance Requirement & 0,87 & 0,79 & 0,24 & \\
Prior Prob. Acceptance & $-2,87$ & $-2,23$ & 13,88 & $*$ \\
Goal Congruence & 0,44 & 0,96 & 14,23 & $*$ \\
Subordinate Conflict & 0,11 & $-0,14$ & 2,96 & \\
\hline
\end{tabular}

\section{Discussion}

The study substantiates three conjectures and empirical findings of earlier studies mentioned above.

1. Austrian managers show a very high profile of participativeness in their leadership behaviour.

2. Czech managers are divergent from their Austrian colleagues, with higher preferences for autocratic leadership styles, higher disagreement with the prescriptions of Vroom/Yetton model and in most of the main effects. 
3. National culture is a 'dominating' factor for the conception and execution of leadership styles.

How can these results be explained for the Czech Republic, which politically brought about a revolution and a reorganisation of its economy from central state planning and state ownership to a market system with a privatisation campaign and an opening for international competition? Did more drastic changes remain on the national level and somehow manage not to penetrate the organisational and individual levels? The latter seems to be the reality, in spite of the fact that individual leaders show a high readiness for flexibility with high scores in their standard deviation. Is a 'configurational' view the best approach to explain stability within a change process? In a simplified picture, we could argue that a model of three main levels would bring us closer to an explanation of this paradoxical situation of stability within a flux of change. The change took place on the societal/political level; the population worked and fought for the right to vote, to exercise the right of government participation, to express more individuality, and to support private ownership. At the individual level, these are indicators that similar values and flexibility exist but do not have a place on the organisational level of private enterprises and it does mean that this potential can be tapped. Perhaps a change at this organisational level can only be brought about when the opportunity is administered congruently, and the 'whole' and its 'parts' can find an optimal (ideal) 'Gestalt'. The existing 'values' need the appropriate situational conditions in order to be transformed into 'actions'.

The situation in Austria after World War II may provide an example. It can be speculated that before the end of the war, culturally and individually preferred leadership styles would not have scored highly on the scale between AI and GII. The state was in the hand of one party and the economy was state-controlled to divide the most available goods among the majority leaving the least for private consumption. When the war was over and democracy was restored in the Austrian economy, the social/economic partnership model was created within the framework of the distribution of political and economic power between the social democrats and the conservatives. This occurred under the leadership of the old political elite from the First Republic (after World War I) who saw no future for the extremes of capitalism and communism. To deal with decisionmaking and conflict resolution, a system was constructed in which all stakeholders had a 'voice' rather than an 'exit' option and consensus (GII) was the preferred strategy of decision making and actions (Szabo et al. 2002). Ideas of partnership did not only govern on the highest political-economic level, but transcended into the daily experience of managers at the organizational level. Laws requiring co-determination - as in West Germany - forced them, as well as their subordinates and their union representatives, to negotiate and agree on norms of cooperation and participation which endorsed new patterns of leadership behaviour. As this process was not achieved in Austria overnight, it 
took its toll on development in the form of 'over consensualism' with delayed adaptation to fast environmental changes in the EU and the world. Just recently, the erosion of the 'two party' political power structure became manifest in the election for the present parliament. This development in based on value changes in the population in favour of more individualism by younger generations born after the two World Wars with no experience of a civil war, poverty and a need for solidarity.

In the Czech Republic, this organisational level could be the bottleneck. It seems crucial that the results of the 'de-statisation' process, with its key elements of privatization and the governance structure in the new 'private' companies, were insufficient. Of all the economic plans launched since 1989, voucher privatization (Kost 1994; Fogel 1994) must rank among the most ambitious. In contrast to other post communist countries, the majority of state property has been, at least formally, transferred to private hands. However, the economic system is often not transparent and enterprise 'owners' are often not real owners but rather managerial cliques having gained their power through connections cultivated in the old regime. Voucher privatization has led to a paradox. Share ownership has been transferred to investment funds, which are private only in their legal form, since they are actually mostly controlled or owned by banks in which the state has a large or even majority stake. The National Property Fund (NPF) owns the state banks, which own the investment funds, which in turn own the majority of companies. The companies are indebted to the same banks, which artificially keep the companies alive because otherwise they would be forced to admit that a large part of their loans are unrecoverable.

In a situation like this, the market system does not bare its teeth in fierce competition against inefficient companies. The managers in protected industries can continue in their former functions and mindset. These managers are characterised by a lack of entrepreneurial spirit and a strong aversion towards taking responsibility. The typical Czech talent for passive resistance leads to delays in necessary restructuring measures. Managers remain order-takers, conservative, risk aversive, operations focused, 'inside' people with low mobility and relying on personal contacts. Proficiency in foreign languages other than Russian is relatively low. Older managers in particular are technically oriented with a propensity to stick to a plan as a rule. They are flexible but their flexibility has a completely different aim: A typical attribute of central command planning was shortage. This included shortages of raw materials, energy, semi-finished products, transport capacities, skilled/unskilled labour force, and investment capital, etc. These predicaments called for competence to improvise and be flexible on the input side of business activities. The market system's accent is on the output side towards consumer and market orientation. 
A market reform alone does not change the governance structure within companies. The Czech government did not initiate legislation based on the experience with co-determination gained in Germany and Austria; the ideals were closer to economic systems along the Anglo-Saxon models, the United States in particular. Perhaps consensus-seeking systems were too close to collective characteristics. It seems that concepts such as freedom, individualism and competition are more appealing to victims of a centralized command system than to politicians who were deceived by their first democratic system and hurt by its complete failure. The unchanged inner hierarchical governance structure of the many directly or indirectly state-owned companies does not force managers to change their habits. In the leadership seminars, managers stated repeatedly: 'I would like to include my subordinates in the decision-making process, but they expect me to make the decisions alone. That way if the decision is wrong, I alone take the blame'. Perhaps a communication problem exists (who tells whom first, what is expected in reality) or the leader forgets his/her responsibility as 'model' and has to be the front runner when it comes to admitting he/she does not have all of the information and therefore needs help and advice and depends on the commitment of subordinates to get the job done effectively.

However not all companies and industries are parts of the privatised but nevertheless state owned conglomerates. Real 'private' companies do exist and they struggle against financial contingencies in a system that makes it nearly impossible for newer, smaller businesses to obtain loans. New loans normally have to be repaid within four years. Additional opportunities can be seen within old industries through new international alliances. Several Czech companies became part of international corporations. In these cases the managers are currently in conflict between the aspirations of the foreign company and their own culturally bound ways of doing things. Here research on the 'cultural standards' (Thomas 1996) of the countries involved - for Germany, Czech Republic, and Austria see Schroll-Machl and Novy (2000), Fink et al. (2001), Novy and Schroll-Machl (2003) - gives insights on how to avoid pitfalls and make the cooperation productive through understanding each other's norms, which govern their behaviour.

An example of a very successful model and partnership is the cooperation between Volkswagen and Skoda (Kunz 1995; Groenwald/Leblane 1996; Dorow/v. Kibed 1997; Maly 2000). In this situation, a so-called Tandem System was installed. For a transition period of several years, a manager from Germany and a manager from the Czech Republic shared the same job. A decision was only authorised when both managers signed a document. This procedure can be seen as a bilateral consensus-seeking programme within one company; namely a structure with some elements of the partnership system on the national level in Austria and on a company level in Germany. The Skoda/VW company is not only successful within the Czech Republic, but also internationally despite 
internal competition against their products manufactured in countries such as Germany, Spain, Mexico and marketed world-wide.

In contrast to the development in large market-driven companies, two other sources of change seem to be effective. First of all, company owners with charismatic behaviour find acceptance within their institutions and take the responsibility for leading their enterprise through difficult conditions. The second stimulus may come from a new breed of young managers who are professionally oriented, some with an MBA education, and capable of speaking western languages such as English, German and French. These young, new managers are not only entrepreneurial, active, flexible, and open-minded, but also, through a typical Czech trait, possess a specific talent for improvising and 'surviving'. They rely on market signals and are risk-takers with strategic planning and vision. These characteristics are optimistic conjectures; we hope that they can become reality and be documented in the future.

\section{References}

Böhnisch, W. (1991): Führung und Führungskräftetraining nach dem Vroom/Yetton-Modell. Stuttgart: Poeschel.

Böhnisch, W./Ragan, J.W./Reber, G./Jago, A.G. (1988): Predicting Austrian leader behavior from a measure of behavioral intent: A cross-cultural replication, in: Dlugos, G./Dorow, W./Weiermair, K. (eds.), Management under differing labour markets and employment systems, Berlin, New York: de Gruyter, 313-322.

Dorow, W./v. Kibed, G.V. (1997): Market entry in Eastern Europe as a challenge for expatriates - Case study: The Volkswagen-Skoda joint venture in the Czech Republic, in: Wagner, D. (Ed.): Bewältigung des ökonomischen Wandels; Entwicklung der Transformationsforschung in Ost und West, München: Hampp, 208-217.

Fink, G./Novy, I./Schroll-Machl, S. (2001): Tschechische, österreichische und deutsche Kulturstandards in der Wirtschaftskooperation, in: Fink, G./Meierewert, S. (eds.): Interkulturelles Management - Österreichische Perspektiven, Wien/New York: Springer, 167-184.

Fogel, D.S. (ed.) (1994): Managing in emerging market economies - Cases from the Czech and Slovak Republics, Boulder, Colorado: Westview Press.

Groenewald, H./Leblane, B. (eds.) (1996): Personalarbeit auf Marktwirtschafts-kurs. Transformationsprozesse im Joint Venture Skoda-Volkswagen, Neuwied: Luchterhand.

Hofstede, G. (1980): Culture's consequences: International differences in work related values, Beverly Hills, CA: Sage.

Hofstede, G. (2001): Culture's consequences: comparing values, behaviors, institutions, and organizations across nations, 2nd ed., Thousand Oaks et al.: Sage.

Hofstede, G./Bond, M.H. (1988): The confucius connection: From cultural roots to economic growth, in: Organizational Dynamics, 16, 4, 4-21. 
House, R.J./Hanges, P./Ruiz-Quintanilla, S.A. (1997): Globe: The global leadership and organizational behavior effectiveness research program, in: Polish Psychological Bulletin, 28, 3, 215-254.

House, R.J./Hanges, P.J./Ruiz-Quintanilla, S.A./Dorfman, P.W./Javidan, M./Dickson, M./Gupta, V. et al. (1999): Cultural influences on leadership and organizations: Project GLOBE, in: Mobley, W.H./Gessner, M.J./Arnold, V. (eds.): Advances in global leadership (Vol. 1), Stamford, Connecticut: JAI Press, 171-233.

House, R.J./Wright, N.S./Aditya, R.N. (1997): Cross-cultural research on organizational leadership: A critical analysis and a proposed theory, In: Earley, P.C./Erez, M. (eds.): New perspectives on international industrial/organizational psychology, San Francisco: New Lexington, 535-625.

Jago, A.G./Reber, G./Böhnisch, W./Maczynski, J./Zavrel, J./Dudorkin, J. (1995): Interkulturelle Unterschiede im Führungsverhalten, in: Kieser, A./Reber, G./Wunderer, R. (eds.): Handwörterbuch der Führung (2nd ed.), Stuttgart: Poeschel, 1226-1239.

Jago, A.G./Vroom, V.H. (1978): Predicting leader behavior from a measure of behavioral intent, in: Academy of Management Journal, 21, 715-721.

Kost, M. (1994): Analyse der Industrieprivatisierung in Polen, Ungarn und der CSFR. Frankfurt: Lang.

Kunz, P. (1995): Hochzeitseuphorie und Alltag im Joint Venture, Change Management by Skoda Volkswagen, in: Dorow, W./Genzel, E. (eds.): EAP Working Paper, Berlin, 6074.

Maczynski, J./Jago, A.G./Reber, G./Böhnisch, W. (1994): Culture and leadership styles: A comparison of Polish, Austrian, and U.S. managers, in: Polish Psychological Bulletin, 25,4, 303-315.

Maly, M. (2000): The Management Strategies of Czech Companies in Transition, in: International Journal of Manufacturing Technology and Management. 1, 4/5, 405-411

Novy, I./Schroll-Machl, S. (2003): Tschechien, in: Thomas, A./Kammhuber, S./SchrollMachl, S. (eds.): Handbuch interkulturelle Kommunikation und Kooperation, Band 2: Länder, Kulturen und interkulturelle Berufstätigkeit, Göttingen: Vandenhoeck/Ruprecht, 90-102.

Reber, G./Jago, A.G. (1997): Festgemauert in der Erde... Eine Studie zur Veränderung oder Stabilität des Führungsverhaltens von Managern in Deutschland, Frankreich, Österreich, Polen, Tschechien und der Schweiz zwischen 1989 und 1996, in: Klimecki, R./Remer, A. (eds.): Personal als Strategie: Mit flexiblen und lernbereiten Human-Ressourcen Kernkompetenzen aufbauen, Bern: Luchterhand, 158-184.

Reber, G./Jago, A.G./Auer-Rizzi, W./Szabo, E. (2000): Führungsstile in sieben Ländern Europas - Ein interkultureller Vergleich, in: Regnet, E./Hofmann, L.M. (eds.): Personalmanagement in Europa, Göttingen: Verlag für Angewandte Psychologie, 154173.

Reber, G./Jago, A.G./Böhnisch, W. (1993): Interkulturelle Unterschiede im Führungsverhalten, in: Haller, M./Bleicher, K./Brauchlin, E./Pleitner, H.-J./Wunderer, R./Zünd, A. (eds.): Globalisierung der Wirtschaft: Einwirkungen auf die Betriebswirtschaftslehre, Bern: Haupt, 217-241.

Schroll-Machl, S./Novy, I. (2000): Beruflich in Tschechien, München: Ham 
Smith, P.B. (1997): Leadership in Europe: Euro-management or the footprint of history?, in: European Journal of Work and Organizational Psychology, 6, 4, 375-386.

Smith, P.B./Dugan, S./Trompenaars, F. (1996): National culture and the values of employees: A dimensional analysis across 43 nations, in: Journal of Cross-Cultural Psychology, 27, 2, 231-264.

Smith, P.B./Peterson, M.F. (1995): Beyond value comparisons: Sources used to give meaning to management events in 30 countries. Paper given at Academy of Management meeting, August 1995, Vancouver, Canada.

Szabo, E./Brodbeck, F.C./Den Hartog, D.N./Reber, G./Weibler, J./Wunderer, R. (2002): The Germanic Europe cluster: where employees have a voice, in: Journal of World Business, 37, 55-68.

Szabo, E./Reber, G./Weibler, J./Brodbeck, F.C./Wunderer, R. (2001): Values and behavior orientation in leadership studies: reflections based on findings in three Germanspeaking countries, in: The Leadership Quarterly, 12, 219-244.

Thomas, A. (1996): Psychologische Wirksamkeit von Kulturstandards im interkulturellen Handeln, in: Thomas, A. (ed.): Psychologie des interkulturellen Handelns, Göttingen: Hogrefe, 107-135.

Trompenaars, F. (1993): Riding the waves of culture: Understanding cultural diversity in business. London: The Economist Books.

Vroom, V.H./Jago, A.G. (1988): The new leadership: Managing participation in organizations. Englewood Cliffs, NJ: Prentice Hall.

Vroom, V.H./Yetton, P.W. (1973): Leadership and decision-making. Pittsburgh: Pittsburgh University Press.

Vroom, V.H./Yetton, P.W./Jago, A.G. (1976): Problem Set No. 5. New Haven: Yale University. 